measurements now have an increased importance, in relation to measurements of selected long-lived isotopes, in assessing possible radiation hazards.

The investigations described in this article form part of a programme of fall-out measurements carried out by the Norwegian Defence Research
Establishment. We wish to acknowledge the help given by the Royal Norwegian Air Force and the Norwegian Meteorological Service in collecting samples of fall-out materials, and by members of the Physics Division of the Norwegian Defence Research Establishment in measuring samples, ete.

\title{
RADIOACTIVE MATERIALS AND THE SKELETON
}

$\mathrm{T}$ HE one-day conference organized by the Bone and Tooth Society on "Radioactive Materials and the Skeleton" included papers on tracer applications of bone-seeking isotopes in biology and in medicine, studies of their biological effects, measurements on rates of deposition of strontium-90 in fallout, the entry of strontium-90 into food, a survey of the radiation doses received by man from environmental sources and some discussion on the biological implications of environmental radiation in so far as bone was concerned. It was, in fact, a very ambitious programme for a short meeting, but it served the very useful purpose of allowing this controversial subject to be seen as a whole.

The first paper, "Anatomical Sites of Deposition of Radioactive Materials in Bone", was given by Prof. P. Lacroix, of the University of Louvain, who has himself been responsible for many fundamental advances in the field of the dynamics of bone growth. $\mathrm{He}$ showed calcium-45 autoradiographs of bones of young and adult dogs and discussed the relevance of the variations in the uptake of calcium throughout the bone to our understanding of the various processes of bone growth and remodelling which take place. Of particular interest was the change in the pattern of uptake with age of the young animal. Soon after birth the major mode of transverse growth of the long bones is by the peripheral deposition of thick layers of bone, the structure of which is still undeterm. ined. This, however, gives way to transverse growth mainly by a process of deposition of rows of osteones under the periosteum, with a different pattern of calcium uptake, which is clearly demonstrated by autoradiography.

In clinical work with bone-seeking isotopes the material for autoradiographic investigation is generally not available and the distribution of the administered isotope must often be determined by external counting methods, which give relatively poor resolution. Much less information is derived than from experimental biological studies but still, as the second paper of the conference, "Bone-seeking Isotopes as Indicators of Bone Turnover", by Drs. G. Bauer and Bo Wendeberg, of Malmö, showed, information can be obtained on the turnover of bone mineral in patho. logical conditions of bone which cannot be obtained by other methods.

A study of the metabolism of strontium, with strontium-85, in human subjects using two volunteers, was next described by Dr. G. E. Harrison, of the Medical Research Council Radiobiological Research Unit, Harwell, in his paper, "The Skeletal Retention of Radioactive Strontium in Man following an Intravenous Dose". Although a dose of only 0.5 uc. strontium-85 was given to each subject, it was possible to follow the retention pattern for one year, first using excretion data and then measurements on retained activity by whole-body counting. The results for the two subjects were remarkably similar, demonstrating the early initial excretion and then a period of relatively rapid loss with a half-life of about 50 days followed by a slow loss from the relatively unexchangeable part of bone. The calculated mean radiation dose to the skeleton over a period of 300 days was $0.23 \mathrm{rad}$.

The three papers of the second session dealt with the biological effects of bone-seeking radioactive isotopes. There is a considerable literature on this subject relating mainly to rates of tumour incidence with different isotopes. Large differences in tumour incidence have been found with different isotopes and different patterns of administration ; but the signifi. cance of such differences are obscure without informa. tion on the distribution of radiation dose in bone and its variation with time, and such information is generally not available.

The first two papers both discussed the histological changes in the bones of growing animals in relation to measured radiation dosage distribution. The first paper, "The Relation of Radiation Damage to Radiation Dose from Strontium-90", by Drs. Sheila Macpherson and Maureen Owen, of the Medical Research Council Group for Research on BoneSeeking Isotopes, Oxford, dealt with the effect of a long-lived isotope in rabbits, whereas the second, "Bone Tumour Production: Dose Response Relation. ships using Phosphorus-32", by Drs. J. P. M. Bensted and N. M. Blackett, of the Physics Department, Institute of Cancer Research, London, discussed the effects of a relatively short-lived isotope in rats. In spite of these differences there was much similarity in the gross biological effects observed and both papers demonstrated the considerable reparative capacities of bone to large radiation doses, of the order of thousands or even tens of thousands of rads. With regard to possible histological antecedents of bone tumour production the two sets of experiments had less in common. Whereas with repeated doses of phosphorus-32, which is a particularly efficient method of producing bone tumours in the rat, an increase in connective tissue in the metaphysis appeared to be closely related to bone tumour production, the experiments with strontium-90 did not demonstrate this. In both sets of experiments the tumours observed arose after very heavy radiation doses, of the order of thousands of rads.

These two papers pointed to the work that remains to be done in this field, rather than to what has been achieved. Certainly the mechanisms of bone tumour production by radiation and the likelihood of bone tumours appearing at low dosage-levels are not yet subjects for easy speculation.

Abnormality in tooth development of young animals given large doses of bone-seeking isotopes is a common finding in experimental work, but relatively little work has been done on the histological 
changes involved. Prof. M. A. Rushton, of Guy's Hospital Medical School, in his paper, "Damage to Dental Tissues in High-Dose Rabbit Experiments", presented a detailed histological study of the response of the developing teeth of weanling rabbits given large doses of strontium-90 (600-1,000 uc. $/ \mathrm{kgm}$.$) .$ The damage observed was very severe; but the radiation doses were extremely high, of the order of tens of thousands of rads. It is greatly to be hoped that work of this calibre can be extended to much lower levels of radiation dose.

The third session was devoted to problems of environmental radioactivity where the radiation dose-rates involved are of the order of a fraction of a rad a year. The first two papers presented dealt with the measurement, and some aspects of the metabolism, of strontium-90. In order to measure the amounts of strontium-90 deposited in Great Britain from fall-out and the resulting labelling of our foodstuffs a considerable organization has had to be built up, whereby samples can be collected from any parts of the country. In their paper, "Strontium-90 in the Environment and in Human Bone", Drs. F. J. Bryant and D. H. Pierson, of Atomic Energy Research Establishment, Harwell, described measurements of strontium-90 content in rain, in drinking water, in human bone and teeth. Apart from the number of test explosions made there are two main factors determining the rate of deposition of strontium-90. The first is the magnitude of the explosions. Debris from explosions of kiloton bombs does not penetrate the tropopause and has a mean residence time in the troposphere of about 30 days. The debris from megaton bombs is, however, injected into the stratosphere and the mean residence time may be as long as 10 years. The second determining factor is the total rainfall over the given period. The strontium-90 content in tap-waters derived from lakes in the United Kingdom in early 1959 was $0.9 \mu \mu \mathrm{c} . / 1$., with lower values for river waters and wells. The highest strontium-90 content of human bones was found in the age-group 0-5 years and had the average value in the femur of $0.83 \mu \mu \mathrm{c} / \mathrm{gm}$. in the second half of 1958 .

Dr. R. Scott Russell, of the Agricultural Research Council Radiobiology Laboratory, Wantage, in his paper, "Radioactive Materials in Foodstuffs", discussed the uptake of strontium-90 in plants and vegetation. He stressed that the major part of the strontium-90 contamination of our foodstuffs came from direct deposition of strontium-90 on to the plant rather than via the soil. It could also be shown that there was only a short interval, not more than about two months, between the deposition of strontium -90 and its appearance in milk, the major source of calcium in our diet in Great Britain. Consequently the strontium-90 content of our food was much more dependent on the rate of deposition of fall-out than on the total accumulated amount.

It must have been very clear from these two papers that the information so far obtained on the deposition of strontium-90 in fall-out and its progress through the food chain is the result of a concentration of highly skilled and intelligent effort and has, in the course of the work, opened up new lines of advance in many fields, from meteorology to agriculture. However, the object of the exercise was to learn something of the biological consequences of fall-out, and the measurement of levels of activity can represent only the preliminary step. The translation of these measured quantities into biological effect is the real challenge.

The values of radiation dose-rate in bone resulting from present levels of fall-out was included in the paper given by Prof. F. W. Spiers, of the University of Leeds, on "Radiation Doses to Bone from all Sources". He first dealt with the problem of where in bone one should measure the radiation dose. Clearly the choice must depend on the degree to which the various tissues comprising bone are significant in the development of late effects. This, however, is not known and the significant dosage values must therefore be uncertain, particularly for the alphaemitting isotopes, on account of their short range. For strontium-90, with its relatively long beta range, there is still a problem, though not so severe as with the alpha emitters.

Prof. Spiers presented tables of the radiation doses received by bone and by soft tissue from cosmic rays and local gamma-rays, from the natural radioactivity of tissues, and from the strontium-90 and cæsium-137 originating in fall-out. Within Great Britain the total dose-rate received from all sources is of the order of 100 millirem per annum, and of this amount cosmic radiation and local environmental radioactivity contribute about 90 per cent. At present levels the strontium-90 contribution to bone does not normally exceed about 4 millirem a year. The contribution to gonadal tissue is extremely small. The major variation in environmental radiation dose received by an individual depends on the gamma-ray contribution from the local environment, but variation in the natural alpha activity of tissues also plays an appreciable part. As a result of these variations in natural radioactivity the dose-rate in bone may vary between individuals by a factor of as much as 2 .

Radiation dosage data such as those presented by Prof. Spiers allow one to come to certain conclusions concerning the comparative somatic effects of the various components of environmental radiation. It is difficult, for example, to avoid the conclusion that if present levels of strontium-90 in bone constitute a hazard, a change in locality may incur a much greater hazard. Beyond such comparative statements it is difficult to go, since the biological data relevant to the late radiation changes in bone refer to radiation doselevels several orders of magnitude higher than that of environmental radiation. Any theoretical treatment of the problem of the somatic effects of small doses involves the widest assumptions-on the part played by specific cell changes, on the significance of gross tissue damage, on the types of tissue at risk and on the part played by the normal homoestatic mechanisms of the body. Nor is it at all certain that a direct attack on the problem, by giving small doses of radiation to large numbers of experimental animals, is justified. In my paper, "The Biological Implications of Radiation Dosage to Bone from Environmental Radioactive Material", I suggested that too much preoccupation with the quantitative aspects of the late effects of low-level irradiation could, in the present state of knowledge, be a great waste of effort and even a hindrance to the better understanding of the subject. It would seem more reasonable to accept the fact of our present ignorance, to rely on comparative radiation dosage data for necessary action and to concentrate experimental effort on a study of the mechanisms, rather than the statistical aspects, of late radiation effects.
L. F. LAMERTON 